\title{
Utilisation of Blood Components in Cardiac Surgery: A Single-Centre Retrospective Analysis with Regard to Diagnosis-Related Procedures
}

\author{
Raoul Georg Geissler ${ }^{a}$ Heinrich Rotering ${ }^{b}$ Hubert Buddendick ${ }^{c}$ \\ Dominik Franz ${ }^{c}$ Holger Bunzemeier ${ }^{c}$ Norbert Roeder ${ }^{c, d}$ Robert Kwiecien ${ }^{\mathrm{e}}$ \\ Walter Sibrowski ${ }^{a}$ Hans H. Scheld ${ }^{b}$ Sven Martens $^{b}$ Peter Schlenke ${ }^{a, f}$ \\ ${ }^{a}$ Institute for Transfusion Medicine and Transplantation Immunology, University Hospital of Münster, Münster, Germany; \\ ${ }^{b}$ Department of Thoracic and Cardiovascular Surgery, University Hospital of Münster, Münster, Germany; \\ ${ }^{c}$ DRG Research Group and Medical Management, University Hospital of Münster, Münster, Germany; \\ ${ }^{\mathrm{d}}$ Board of Management, University Hospital of Münster, Münster, Germany; \\ e Institute for Biostatics and Clinical Research, University of Münster, Münster, Germany; \\ ${ }^{f}$ Department of Blood Group Serology and Transfusion Medicine, Medical University Graz, Austria
}

\section{Keywords}

Cardiac surgery · Haemotherapy · Blood supply ·

Blood transfusion - Patient blood management

\section{Summary}

Background: More blood components are required in cardiac surgery than in most other medical disciplines. The overall blood demand may increase as a function of the total number of cardiothoracic and vascular surgical interventions and their level of complexity, and also when considering the demographic ageing. Awareness has grown with respect to adverse events, such as transfusion-related immunomodulation by allogeneic blood supply, which can contribute to morbidity and mortality. Therefore, programmes of patient blood management (PBM) have been implemented to avoid unnecessary blood transfusions and to standardise the indication of blood transfusions more strictly with aim to improve patients' overall outcomes. Methods: A comprehensive retrospective analysis of the utilisation of blood components in the Department of Cardiac Surgery at the University Hospital of Münster (UKM) was performed over a 4-year period. Based on a medical reporting system of all medical disciplines, which was established as part of a PBM initiative, all transfused patients in cardiac surgery and their blood components were identified in a diagnosis- and medical procedure-related system, which allows the precise allocation of blood consumption to interventional procedures in cardiac surgery, such as coronary or valve surgery. Results: This retrospective single centre study included all in-patients in cardiac surgery at the UKM from 2009 to 2012, corresponding to a total of 1,405-1,644 cases per year. A blood supply was provided for $55.6-61.9 \%$ of the cardiac surgery patients, whereas approximately $9 \%$ of all inpatients at the UKM required blood transfusions. Most of the blood units were applied during cardiac valve surgery and during coronary surgery. Further surgical activities with considerable use of blood components included thoracic surgery, aortic surgery, heart transplantations and the use of artificial hearts. Under the measures of PBM in 2012 a noticeable decrease in the number of transfused cases was observed compared to the period from 2009 to 2011 before implementation of the PBM initiative (red blood cells $p<0.002$; fresh frozen plasma $p<0.0006$; platelets $p<0.00006$ ). Conclusion: Until now, cardiac surgery comes along with a significant blood supply. By using a case-related data evaluation programme, the consumption of each blood component can be linked to clinical performance groups and, if necessary, to individual patients. Based on the results obtained from this retrospective analysis, prospective studies are underway to begin conducting target / actual performance comparisons to better understand the individual decision-making by the attending physicians with respect to transfusions.

\section{KARGER}

Fax +497614520714

\section{() 2015 S. Karger GmbH, Freiburg}

$1660-3796 / 15 / 0422-0075 \$ 39.50 / 0$
PD. Dr. Raoul Georg Geissler

Institut für Transfusionsmedizin und Transplantationsimmunologie Universitätsklinikum Münster

Domagkstraße 11, 48149 Münster, Germany

georg.geissler@ukmuenster.d 


\section{Introduction}

In many hospitals that provide comprehensive medical care, the usage of blood components during cardiac surgery is much greater than the average blood product demand in most other medical disciplines [1-6]. Today, blood transfusions have become more and more accepted as a major quality indicator in cardiac surgery [79]. In Germany, the number of cardiac operations continues to increase, even in patients older than 80 years [10]. This trend has been partially affirmed in other countries as well [11]. Due to the increased number of surgical interventions and their progressive complexity, particularly in higher-developed countries $[1,4,12-$ 16], the demand for blood products has increased globally, as noted by a demographic analysis [17]. Additionally, older patients require more blood transfusions $[14,18,19]$ as a result of progress in medical sciences and therapeutic options [17]. Additionally, the demographic ageing of the population in higher developed countries may even reduce the number of younger individuals without illness who have preferentially been recruited as voluntary blood donors $[4,12,14,15,20,21]$.

Several anticipatory efforts to moderate the consequences of these demographic changes have been made by blood donation establishments and hospital-related programmes of patient blood management $(\mathrm{PBM})[6,22,23]$. For example, the prophylactic treatment of pre-operative anaemia with iron deficiency through the intravenous application of iron was applied to reduce the perioperative [23-26] and intensive care demand [27] of red blood cell (RBC) transfusions. In the past, autologous RBC transfusions were installed to reduce the use of allogeneic blood and its potential adverse effects $[28,29]$. Additionally, the general improvement in surgical techniques and several blood loss-minimising techniques, such as intra-operative blood salvage, have been implemented, particularly in cardiothoracic surgery, in which blood use has traditionally been high [23]. Moreover, liberal or restrictive transfusion regimens have been compared in intensive care units or at-risk cardiovascular patients $[30,31]$. In these studies, patients treated with a restrictive transfusion policy, which indicates a RBC supply only for patients with symptoms of anaemia or with haemoglobin levels below $8 \mathrm{~g} / \mathrm{dl}$, did not suffer from a higher morbidity and/or mortality than the patients with a liberal transfusion threshold (haemoglobin up to $10 \mathrm{~g} / \mathrm{dl}$ ). Furthermore, the reduction of RBC transfusions in cardiac surgery could also be realised by point-of-care diagnostics to prevent or treat coagulopathy at an early stage. [32].

To avoid unnecessary or inappropriate blood use, several years ago national and international transfusion guidelines have been established in numerous medical disciplines, including cardiac surgery. These guidelines are subjected to a systematic review process by a panel of experts to safeguard state-of-the-art methods in science and technology [33-35]. However, there is an increasing body of evidence suggesting a significant gap between the release of guidelines and their acceptance by professional authorities who are responsible for ensuring their in-house implementation. Therefore, transfusion practices in general and for cardiac surgery continue to vary from hospital to hospital and from physician to physician [9, 32, 35-37].
To further improve blood utilisation at the University Hospital Münster (UKM), the board of management decided to implement a PBM programme in close cooperation with experts in transfusion medicine and anaesthesiology. One of the long-term objectives of this programme was to improve adherence to the (inter-)national guidelines and in-house transfusion algorithms aiming at the avoidance of needless blood transfusions and transfusion-related adverse events and to reduce the transfusion-associated costs. To achieve this goal, a retrospective study was performed linking blood utilisation to diagnosis- or medical procedure-driven groups in order to analyse the blood component consumption within all medical departments of the UKM in detail [6].

\section{Material and Methods}

\section{Database}

The Institute of Transfusion Medicine and Transplantation Immunology documents each actual transfusion of allogeneic blood components on a percase basis for all in-patients at the UKM. These data comprise the type of blood component (RBCs, fresh frozen plasma (FFP) and platelets collected by apheresis (PLTs)), the number of issued and transfused bags and the dates of production, issuance and application for all medical departments. Autologous blood donations $\mathrm{w}$ ere excluded from this report due to low donation numbers. The blood components of the in-patients who stayed in the hospital over the turn of the year were numerated for the year of discharge. After the editorial deadline, the consumption data reported in this study may vary by approximately $0.1 \%$ due to slight changes in the final allocation of the cases or transfusions to the Department of Cardiac Surgery according to the terminal reconciliation with the health insurances. The privacy and security of the patients' data presented in this article were protected by the precautionary anonymisation of all patient data.

\section{Data Processing}

The data processing considered various case-related data (e.g., gender, age, length of stay, diagnoses, medical procedures, diagnosis-related groups, costs for the different types of blood components etc.). These case-related patient data were allocated to the performing medical department within a standardised process developed by the Department of Medical Management [38, 39]. This allocation represents an algorithm that ensures a comprehensible and reliable assignment of cases to enable the hospital management to plan, monitor and control the number of operations during in-patient treatment. The main criteria of the allocation are: the complexity of a surgical procedure and the length of stay in a special medical department, e.g., in the Department of Cardiac Surgery [38, 39]. After allocation to the medical department of main performance, the case-related data undergoes a further classification structure to create a transparent platform of information for the clinician. This system of clinical performance groups (KLG = 'klinische Leistungsgruppe(n)') was developed in the Department of Medical Management [38]. The aim of the KLG system is to support all departments of the UKM, using administrative and economic data on the department level. As a result, the structure of the KLG system is independent of the G-DRG (German diagnosis-related groups) system. This separation is very important to support the different departments by monitoring and controlling their clinical data. The structure of the G-DRG-system changes every year. If the case-related data were reported based on G-DRGs, the case reports of different years could not be compared. To fulfil its purpose, the KLG system for the Department of Cardiac Surgery consists of 15 main clinical performance groups (e.g., heart transplantation, aortic surgery, valve surgery etc.). If necessary, the main groups can be further differentiated into subclasses (valve surgery: conventional or minimally invasive procedures). Within the KLG system, each in-patient case is assigned to only one group of clinical performance. The allocation process follows a given hierarchy that considers complex cases first. Cases of lower complexity or non-surgical treatments are ac- 
Table 1. Number of transfused patients and blood in cardiac surgery

\begin{tabular}{|c|c|c|c|c|c|c|c|c|c|}
\hline \multirow[t]{2}{*}{ Patients } & \multicolumn{3}{|l|}{$\mathrm{RBC}$} & \multicolumn{3}{|l|}{ FFP } & \multicolumn{3}{|l|}{ PLT } \\
\hline & $\mathrm{T} / \mathrm{A}$ & units & $\mathrm{U} / \mathrm{T}$ & $\mathrm{T} / \mathrm{A}$ & units & $\mathrm{U} / \mathrm{T}$ & $\mathrm{T} / \mathrm{A}$ & units & $\mathrm{U} / \mathrm{T}$ \\
\hline $2009(\mathrm{~N}=1,533)$ & $849(55.4 \%)$ & 5,998 & $7.1 \pm 9.9$ & $384(25.0 \%)$ & 4,276 & $11.1 \pm 15.1$ & $319(20.8 \%)$ & 914 & $2.9 \pm 3.9$ \\
\hline $2010(\mathrm{~N}=1,505)$ & $912(60.6 \%)$ & 6,965 & $7.6 \pm 10.2$ & 444 (29.5\%) & 5,331 & $12.0 \pm 14.9$ & 405 (26.9\%) & 1,147 & $2.8 \pm 3.1$ \\
\hline $2011(\mathrm{~N}=1,405)$ & $839(59.7 \%)$ & 6,691 & $8.0 \pm 10.1$ & $336(23.9 \%)$ & 4,175 & $12.4 \pm 16.4$ & $269(19.1 \%)$ & 887 & $3.3 \pm 4.0$ \\
\hline $2012(\mathrm{~N}=1,644)$ & $886(53.9 \%)^{\mathrm{a}}$ & 7,253 & $8.1 \pm 11.7$ & $369(22.4 \%)^{\mathrm{a}}$ & 5,106 & $13.8 \pm 18.5$ & $296(18.0 \%)^{\mathrm{a}}$ & 994 & $3.4 \pm 3.9$ \\
\hline
\end{tabular}

counted for in descending order. The KLG system provides necessary information on the Department of Cardiac Surgery regarding the numbers and the case mix within the main clinical performance groups and allows comparing these data with those of the previous year. In every group, additional specific patient data are displayed (e.g., diagnoses, medical procedures, G-DRG etc.). All steps of the methods described are based on individually developed structures and processes of the UKM

\section{Data Reporting}

The data are updated monthly, allowing for a representation of the number of transfused blood components per time interval for each department of the UKM and for each KLG. Comparisons to the preceding year's figures are issued quarterly and annually. Therefore, a longitudinal analysis of the use of blood components comparing different years of observation is possible. A further differentiation according to individual diagnoses (e.g., surgical or non-surgical treatment; specific medical procedures; age; gender; special features, such as the duration of mechanical ventilation) can be realised without difficulty, as can the analysis of single cases. Thus, a differentiated view of the specific circumstances pertaining to any blood supply in the hospital is possible [38].

\section{Statistical Methods}

The comparison of the two time periods (2009-2011 vs. 2012) is carried out using Fisher's exact test for qualitative variables. All tests are two-sided. If a p value is smaller than $5 \%$, we conclude that a statistically noticeable difference can be observed. We do not use the term 'significant' with intent, since this is a retrospective analysis - thus the results of the statistical tests are to be interpreted in an exploratory, and not in a confirmatory sense - and since an adjustment for multiple testing is not applied. Categorical variables are described in absolute and relative frequencies. Continuous variables are described by mean values.

\section{Results}

The data used in this retrospective analysis included all in-patient data from 2009 to 2012 who were treated in the Department of Cardiac Surgery at the UKM; this group comprised an average of approximately $3 \%(2.9-3.3 \%)$ of all UKM in-patients. The case mix index of this discipline continuously increased during the observation time (2009: 6.68, 2010: 7.13, 2011: 7.31 and 2012: 7.39). In our institution, approximately one fourth of all RBC (25.7$29.3 \%)$ and FFP units (20.0-30.7\%) and one eighth (12.0-14.3\%) of all PLT units are used for cardiac surgery patients. Understandably, the department generates approximately $20 \%$ (17.6-21.2\%) of the total costs associated with the allogeneic blood supply, which represents the second highest 'position' of all UKM disciplines (the first position is occupied by the Department of Haematology/ Oncology).

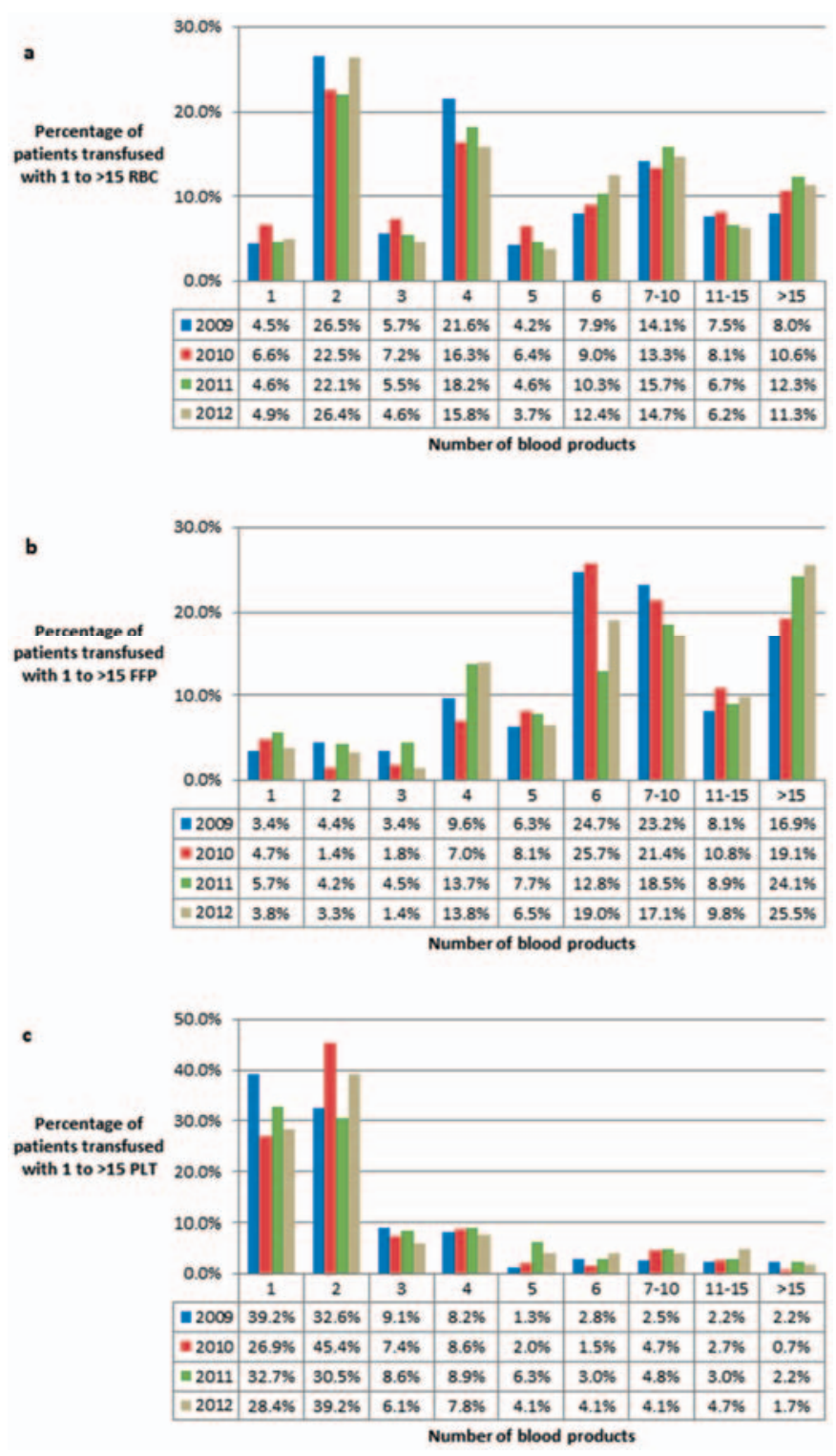

Fig. 1. Clustered numbers of transfused blood units in cardiac surgery. a RBCs, b FFP, $\mathbf{c}$ PLTs.

In addition, we analysed the proportion of patients who received blood transfusions and calculated the mean consumptions of RBC, FFP and PLT units per transfused patient (table 1). We observed a relatively constant demand of blood supply over the study 
Table 2. Gender distribution for transfused patients in cardiac surgery

\begin{tabular}{|c|c|c|c|c|c|c|c|c|c|c|c|c|c|c|}
\hline \multicolumn{3}{|c|}{ Patients } & \multicolumn{4}{|l|}{$\mathrm{RBC}$} & \multicolumn{4}{|l|}{ FFP } & \multicolumn{4}{|l|}{ PLT } \\
\hline \multirow[t]{2}{*}{ year } & \multirow[t]{2}{*}{ F, no. } & \multirow[t]{2}{*}{ M, no. } & \multicolumn{2}{|l|}{$\mathrm{T} / \mathrm{A}$} & \multicolumn{2}{|c|}{$\mathrm{U} / \mathrm{T}$} & \multicolumn{2}{|l|}{$\mathrm{T} / \mathrm{A}$} & \multicolumn{2}{|l|}{$\mathrm{U} / \mathrm{T}$} & \multicolumn{2}{|l|}{$\mathrm{T} / \mathrm{A}$} & \multicolumn{2}{|c|}{$\mathrm{U} / \mathrm{T}$} \\
\hline & & & $\mathrm{F}$ & $\mathrm{M}$ & $\mathrm{F}$ & $\mathrm{M}$ & $\mathrm{F}$ & $\mathrm{M}$ & $\mathrm{F}$ & $\mathrm{M}$ & $\mathrm{F}$ & $\mathrm{M}$ & $\mathrm{F}$ & M \\
\hline 2009 & 485 & 1,048 & 65.2 & 50.9 & 6.4 & 7.5 & 26.4 & 24.4 & 9.1 & 12.1 & 21.0 & 20.7 & 2.7 & 2.9 \\
\hline 2010 & 457 & 1,048 & 66.1 & 58.2 & 6.9 & 8.0 & 28.2 & 30.1 & 10.2 & 12.7 & 26.7 & 27.0 & 2.5 & 3.0 \\
\hline 2011 & 470 & 935 & 63.6 & 57.8 & 7.3 & 8.4 & 23.4 & 24.2 & 10.9 & 13.1 & 16.6 & 20.4 & 3.4 & 3.3 \\
\hline 2012 & 543 & 1,101 & 59.1 & 51.3 & 7.1 & 8.8 & 21.9 & 22.7 & 12.7 & 14.4 & 15.8 & 19.1 & 3.5 & 3.3 \\
\hline
\end{tabular}

$\mathrm{F}=$ Female, $\mathrm{M}=$ male; $\mathrm{T} / \mathrm{A}=$ proportion of transfused patients out of all in-patients; $\mathrm{U} / \mathrm{T}$ = average amount of units in transfused patients.

Table 3. Proportion of transfused patients and blood consumption in a total of eight clinical performance groups of cardiac surgery

\begin{tabular}{|c|c|c|c|c|c|c|c|c|}
\hline & \multicolumn{2}{|c|}{2009} & \multicolumn{2}{|l|}{2010} & \multicolumn{2}{|l|}{2011} & \multicolumn{2}{|l|}{2012} \\
\hline & $\mathrm{T} / \mathrm{A}$ & $\mathrm{U} / \mathrm{T}$ & T/A & $\mathrm{U} / \mathrm{T}$ & T/A & $\mathrm{U} / \mathrm{T}$ & $\mathrm{T} / \mathrm{A}$ & $\mathrm{U} / \mathrm{T}$ \\
\hline \multicolumn{9}{|l|}{$\mathrm{RBC}$} \\
\hline Coronary surgery & 66.9 & 5.2 & 75.8 & 5.5 & 73.0 & 6.2 & 70.4 & 5.5 \\
\hline Valve surgery & 75.5 & 7.1 & 85.3 & 8.2 & 83.9 & 8.9 & 70.7 & 9.0 \\
\hline Thoracic surgery & 32.2 & 7.9 & 37.4 & 7.6 & 31.7 & 6.5 & 27.6 & 6.8 \\
\hline Cardiac devices & 89.9 & 19.0 & 100.0 & 26.4 & 94.4 & 24.9 & 100.0 & 27.5 \\
\hline Heart transplantation & 88.9 & 30.8 & 100.0 & 35.6 & 100.0 & 35.4 & 100.0 & 41.4 \\
\hline Aortic surgery & 75.0 & 11.3 & 79.1 & 7.6 & 91.8 & 12.0 & 79.2 & 14.3 \\
\hline Children $<16$ years & 80.3 & 4.8 & 80.3 & 3.1 & 79.3 & 4.8 & 63.6 & 3.5 \\
\hline Others & 14.7 & 7.5 & 12.7 & 6.6 & 20.4 & 5.1 & 20.8 & 6.3 \\
\hline \multicolumn{9}{|l|}{ FFP } \\
\hline Coronary surgery & 20.8 & 8.8 & 30.5 & 9.0 & 19.0 & 11.1 & 20.6 & 10.3 \\
\hline Valve surgery & 38.1 & 9.3 & 45.0 & 12.1 & 32.7 & 11.4 & 31.7 & 13.5 \\
\hline Thoracic surgery & 9.5 & 17.1 & 10.9 & 15.6 & 9.2 & 10.7 & 7.1 & 13.4 \\
\hline Cardiac devices & 74.1 & 27.6 & 90.9 & 24.3 & 83.3 & 28.9 & 92.2 & 19,3 \\
\hline Heart transplantation & 77.8 & 31.5 & 100.0 & 30.9 & 100.0 & 31.0 & 100.0 & 27.7 \\
\hline Aortic surgery & 71.4 & 13.1 & 55.8 & 12.3 & 79.6 & 16.0 & 63.9 & 23.6 \\
\hline Children $<16$ years & 72.4 & 6.3 & 69.0 & 7.1 & 68.3 & 7.3 & 53.2 & 5.3 \\
\hline Others & 5.3 & 11.2 & 3.1 & 7.2 & 3.0 & 8.6 & 2.8 & 18.7 \\
\hline \multicolumn{9}{|l|}{ PLT } \\
\hline Coronary surgery & 19.4 & 2.0 & 33.7 & 2.0 & 17.8 & 2.9 & 20.7 & 2.0 \\
\hline Valve surgery & 29.4 & 2.2 & 43.5 & 2.5 & 26.7 & 3.2 & 23.0 & 3.4 \\
\hline Thoracic surgery & 7.5 & 5.3 & 7.8 & 4.2 & 6.8 & 2.1 & 5.5 & 4.4 \\
\hline Cardiac devices & 55.6 & 6.0 & 81.8 & 5.8 & 55.6 & 7.9 & 76.2 & 4.7 \\
\hline Heart transplantation & 83.3 & 5.0 & 100.0 & 7.8 & 100.0 & 6.9 & 100.0 & 7.9 \\
\hline Aortic surgery & 64.3 & 2.4 & 46.5 & 3.0 & 73.5 & 3.3 & 54.2 & 4.8 \\
\hline Children $<16$ years & 51.3 & 4.3 & 29.6 & 2.3 & 37.8 & 2.6 & 31.2 & 1.7 \\
\hline Others & 4.3 & 2.8 & 1.2 & 4.7 & 1.7 & 3.2 & 1.7 & 7.8 \\
\hline
\end{tabular}

period of 4 years, resulting in a frequency of $>50 \%$, about $25 \%$ and about $20 \%$ of all cardiac surgery patients receiving RBC, FFP and PLT units, respectively. The overall average number of blood units per transfused patient amounted to approximately 8 RBC, 12 FFP and 3 PLT units (table 1). However, on January 1, 2012 the PBM initiative started at our hospital with the introduction of a periodical reporting system for blood component utilisation combined with interviews of the transfusion commissioned clinicians. Therefore, we observed a noticeable decrease in the number of transfused cases in 2012 compared to the period from 2009 to 2011 without PBM measures (transfusions of RBCs $\mathrm{p}<0.002$; of FFP $\mathrm{p}<0.0006$; and of PLTs $\mathrm{p}<0.00006$ ).

In figure 1, the spectrum of the total units for each blood component given per transfused case is shown in greater detail. Notably, the data suggest that RBC units are ordered more likely in double packs than FFP or PLT units. Approximately 5 and $25 \%$ of the transfused patients received only one and two RBC units during their hospital stay, respectively, whereas almost $20 \%$ of the transfused patients in cardiac surgery were treated with more than 10 RBC units. The transfusion pattern of FFP utilisation was different in that 
roughly $10 \%$ of the transfused patients received 1-3 FFP units, corresponding to approximately $250-750 \mathrm{ml}$ of volume. Similar to RBCs, a significant portion of the cardiac surgery patients (up to one third) were treated with more than 10 FFP units. Most of our patients required no PLT transfusion during cardiac surgery. If appropriate, two thirds of the patients generally receive one or two units.

Approximately $85 \%$ of all in-patients at the Department of Cardiac Surgery were 40 to 80 years old. As shown in figure 2, using the example of the RBC supply, there was an indicator that older patients (70-80 years) have a higher likelihood of requiring trans-

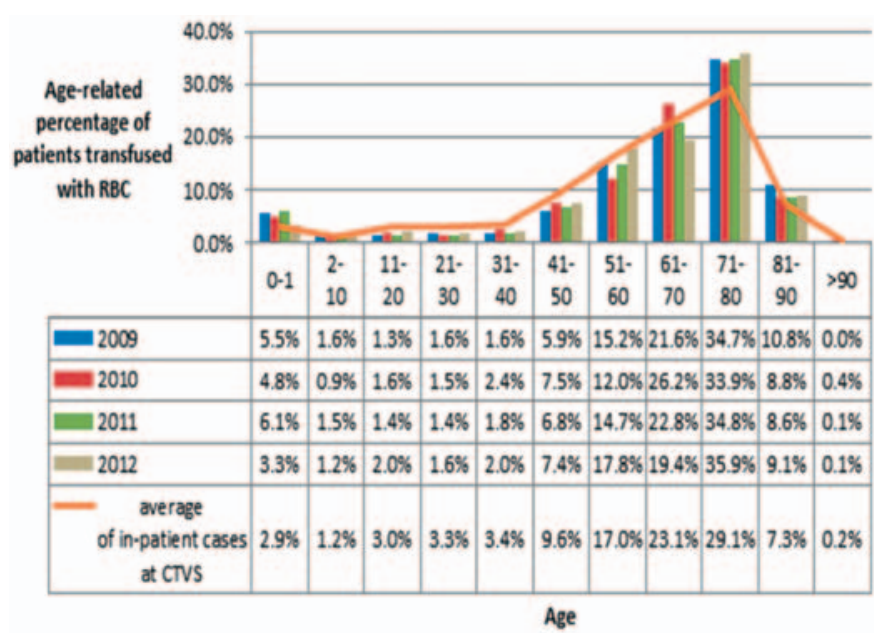

Fig. 2. Age distribution of transfused patients in cardiac surgery (exemplary for RBC supply). fusion or receive greater amounts of blood units in the case of transfusion. During the first year of life, children more frequently require a blood supply. The gender distribution of all in-patients, the frequency of transfused patients and the applied blood units are indicated in table 2. As expected, the majority of the cardiac surgery patients were male (nearly two thirds). The conspicuous feature in regard to overall blood consumption was the higher rate of females receiving $\mathrm{RBC}$ transfusions, which we observed continuously during the entire study period. In contrast, the demand for FFP and PLT units was basically identical in both genders. Irrespective of receiving RBC or FFP units, men require more units per case, on average, than women.

All cardiac surgery patients enrolled in this retrospective study were assigned to 16 clinical performance groups. For the 7 most frequent and important clinical performance groups (coronary surgery, cardiac valve surgery, thoracic surgery, aortic surgery, cardiac transplantation, use of cardiac devices and cardiac surgery in children younger than 16 years), the percentage of transfused patients and the average number of blood units per transfused case are given in table 3 . Not surprisingly, the highest transfusion rates were indicated in patients with heart transplantations (nearly $100 \%$ for RBCs), followed by cases that used cardiac assist devices (approximately $75-100 \%$ ), independent of the type of blood component. In line with this observation, most of the blood units per patient were required for heart transplantations (about $30 \mathrm{RBC}$ units) and the use of cardiac assist devices ( $>20$ RBC units), followed by aortic, valve and thoracic surgeries (about 10, 8 and 7 RBC units, respectively).
Table 4. Proportion of transfused patients and blood consumption in the clinical subgroups of coronary surgery and valve surgery

\begin{tabular}{|c|c|c|c|c|c|c|c|c|}
\hline & \multicolumn{2}{|l|}{2009} & \multicolumn{2}{|l|}{2010} & \multicolumn{2}{|l|}{2011} & \multicolumn{2}{|l|}{2012} \\
\hline & $\mathrm{T} / \mathrm{A}$ & $\mathrm{U} / \mathrm{T}$ & $\mathrm{T} / \mathrm{A}$ & $\mathrm{U} / \mathrm{T}$ & $\mathrm{T} / \mathrm{A}$ & $\mathrm{U} / \mathrm{T}$ & $\mathrm{T} / \mathrm{A}$ & $\mathrm{U} / \mathrm{T}$ \\
\hline \multicolumn{9}{|l|}{ Coronary surgery } \\
\hline \multicolumn{9}{|l|}{$\mathrm{RBC}$} \\
\hline Conventional & 68.4 & 5.3 & 76.9 & 5.6 & 74.2 & 6.4 & 72.1 & 5.6 \\
\hline Minimally invasive & 47.7 & 4.1 & 50.0 & 2.8 & 55.3 & 3.4 & 59.3 & 5.1 \\
\hline \multicolumn{9}{|l|}{ FFP } \\
\hline Conventional & 21.1 & 9.1 & 31.0 & 9.1 & 20.1 & 11.5 & 21.0 & 10.9 \\
\hline Minimally invasive & 13.6 & 5.0 & 23.8 & 5.8 & 5.3 & 4.5 & 16.9 & 6.5 \\
\hline \multicolumn{9}{|l|}{ PLT } \\
\hline Conventional & 19.6 & 2.0 & 35.0 & 2.0 & 18.7 & 3.0 & 22.7 & 2.0 \\
\hline Minimally invasive & 15.9 & 1.6 & 9.5 & 1.5 & 10.5 & 1.2 & 6.8 & 3.0 \\
\hline \multicolumn{9}{|l|}{ Valve surgery } \\
\hline \multicolumn{9}{|l|}{$\mathrm{RBC}$} \\
\hline Conventional & 77.4 & 7.0 & 88.1 & 8.0 & 85.2 & 8.6 & 71.4 & 8.2 \\
\hline Minimally invasive & 60.0 & 7.0 & 66.7 & 6.6 & 76.9 & 5.9 & 66.7 & 10.7 \\
\hline \multicolumn{9}{|l|}{ FFP } \\
\hline Conventional & 36.7 & 9.6 & 45.5 & 11.1 & 30.8 & 11.1 & 29.6 & 13.3 \\
\hline Minimally invasive & 20.0 & 5.6 & 28.6 & 8.3 & 15.4 & 10.0 & 33.3 & 16.0 \\
\hline \multicolumn{9}{|l|}{ PLT } \\
\hline Conventional & 29.0 & 2.3 & 44.0 & 2.5 & 24.7 & 2.9 & 22.6 & 3.2 \\
\hline Minimally invasive & 16.0 & 1.0 & 28.6 & 2.2 & 15.4 & 1.5 & 16.7 & 2.0 \\
\hline
\end{tabular}


The blood utilisation in the coronary surgery and valve surgery clinical subgroups are depicted in greater detail in table 4. In minimally invasive coronary surgery, fewer patients require blood transfusions, and these transfusions comprise less blood units compared to conventional treatment. In valve surgery, this effect was less pronounced but was also verifiable for minimally invasive procedures.

\section{Discussion}

Several efforts have been made to assess and standardise the utilisation of blood components in cardiac surgery [33, 34]. However, the application of blood components is controversially discussed in this discipline, particularly the usefulness of general transfusion triggers, such as a haemoglobin level less than $7-8 \mathrm{~g} / \mathrm{dl}$ [40]. Transfusions of RBCs in cardiac surgery might be reduced when transfusion-responsible physicians follow transfusion algorithms more strictly and consider the impact of point-of-care diagnostics. Therefore, both the implementation of specific transfusion guidelines and standard operating procedures for hospital-internal use are highly recommended $[32,41]$. However, until now, standardised and restrictive transfusion regimens have not been realised extensively in cardiac surgery, particularly in older patients who commonly suffer from several co-morbidities.

Consequently, the PBM programme in Münster was initiated to investigate compliance with the German guidelines and their defined restrictive indication criteria for transfusions. Based on a computerised recording of all transfusion cases, we periodically report on the utilisation of blood components to the clinical departments for different groups of their medical diagnoses and procedures. We discuss these written reports with the responsible physicians of each department and continuously and collectively pursue the development of the consumption figures of blood products over time. Therefore, each department is empowered to prevent unnecessary transfusions in its medical sub-disciplines if required.

Without a doubt, many interventions in cardiac surgery are not feasible without a blood supply. Understandably, blood transfusions contribute significantly to saving lives. However, according to several cardiosurgical studies using other interventions, a reduction or even an avoidance of allogeneic blood transfusions is discussed to improve the patients' outcome $[9,36,37]$. Thus, blood transfusions in cardiac surgery might be associated with augmented morbidity and mortality, whereas the cause-and-effect relations remain unknown.

Currently, a very low risk for transfusion-associated infections with viruses such as HIV, HBV and HCV has been achieved using very sensitive and specific nucleic acid amplification tests. However, several authors believe that the transfusion of allogeneic RBCs is burdened with adverse effects other than infectious risks, and there are suspicions that these transfusions are associated with an increase of the rates of myocardial infarction, atrial fibrillation, stroke, renal failure and prolonged artificial ventilation as well as with a prolonged hospital stay [42-46]. However, the results ob- tained from these retrospective analyses are not self-explanatory and do not allow any conclusions concerning the causality between blood supply and increased morbidity or mortality. On the other hand, prospective studies were rarely performed and often lacked the randomisation or sufficient statistical power due to the size of the patient cohorts. In a recently published detailed sub-analysis of the prospective randomised TRACS study [36], Galas et al. [47] compared the outcomes of 502 patients with and without RBC transfusions in the first $72 \mathrm{~h}$ after elective coronary artery bypass graft. There were no differences except for a prolonged hospital stay, between the transfused and non-transfused patients. In contrast to our study, the patients in the above mentioned study were supplied with 'fresh' RBCs that had been stored up to 3 days in a simple citrate solution without leukodepletion, which may bear an inherent risk for transfusion-associated adverse events, making comparisons with other studies difficult.

A patient's outcome after cardiac surgery is closely related to the fact if post-operative infectious complications, such as nosocomial pneumonia, mediastinitis and sepsis, (relative risk 3.5; p < 0.001) developed or not. As suggested by Leal-Noval et al. [48], this complication rate might be associated with blood transfusions in a dose-dependent manner. In this study, patients who received blood components had a higher risk of death ( 13.3 vs. $8.9 \%$; $p<0.001)$ and longer stays in intensive care units $(6.1 \pm 7.2$ vs. $3.7 \pm 2.8$ days; $\mathrm{p}<0.001)$ compared to patients who were not transfused [48].

The general shortage of volunteer blood donations, obvious transfusion-related complications (such as ABO-incompatible transfusions), the spectrum of adverse events mentioned above and increasing transfusion-related costs were all driving forces to promote the development of a more evidence-based haemotherapy. This rationale is the basis of all recently initiated programmes regarding PBM in cardiac surgery, such as that of Shander et al. [22] in Australia or that of our institution. To this end, the UKM initiated a retrospective analysis of blood consumption in cardiac surgery considering specific diagnosis- and procedure-related performance groups (KLGs). The transfusion rate and the absolute number of transfused blood components depend on the severity of the patients' disease, the complexity of the surgical intervention (e.g., heart transplantation) and other accompanying circumstances (e.g., secondary diagnoses). Concomitant diseases, such as myocardial infarction, chronic obstructive pulmonary disease, arterial hypertension, diabetes mellitus, obesity, chronic renal failure and acute or chronic coagulopathies, are critical factors with more or less impact on the pre-operative status of anaemia and/or the overall need for a blood supply. Furthermore, the proportion of emergency patients, surgical procedures with high urgency, and intra-operative factors (e.g., the extension of operation, time of cardiopulmonary bypass circulation and time of ischaemia) are additional variables that may influence the patients' outcome and their stress resistance with respect to allogeneic blood transfusion. The co-morbidities and additional confounding factors mentioned above could not be considered in this retrospective analysis. Therefore, the results presented here can hardly be compared to other university hospitals or to the nationwide average and, consequently, are not suitable as a benchmark. 
The data obtained in our retrospective analysis are in agreement with previously published results concerning the overall blood consumption of RBC, FFP and PLT units in cardiac surgery [1-6, 13]. The percentage of patients requiring RBC, FFP or PLT units noticeably decreased after the introduction of the PBM measures in January 1, 2012, whereas significantly more blood (RBCs) per patient was provided in 2012 (7,253 RBC units) compared to 2009 (5,998 RBC units), which might reflect the above mentioned complexity factor. More females than males received RBCs during cardiac surgery (two thirds vs. one half), which may be due to the higher incidence of pre-operative anaemia or a smaller haemoglobin margin in females. Fortunately, our data management system allows the validation of further detailed information regarding patient subgroups or individual patients in clinical performance groups, as illustrated in the 'Results' section. This type of resolution makes it possible to correlate blood consumption closely with the level of a specific diagnosis. As expected, the highest transfusion demand was found in heart transplantation and the use of cardiac devices, both with respect to the proportion of transfusion cases and the number of transfused units. However, due to their infrequency, the total con- sumption of blood units per year is rather negligible, whereas the conventional cardiac valve surgery and coronary surgery are the two major surgical procedures that are responsible for at least 50$60 \%$ of the blood supply required. Meanwhile, we were able to demonstrate that upcoming minimally invasive surgical techniques are associated with reduced blood consumption.

Based on our data, it makes sense to continue PBM measures in cardiac surgery because it is one of the major medical disciplines with high transfusion needs. In respect to the demographic changes and the medical progress in this field, a continuous increase in cardiac surgery is expected worldwide. The joint efforts of interdisciplinary teamwork will continue to identify causes of unnecessary blood transfusions, such as deviations from in-house transfusion policies, to intensify the treatment of pre-operative anaemia and to improve bloodless surgical techniques.

\section{Disclosure Statement}

The authors declare that there are no conflicts of interest, sponsorships, or funding arrangements related to this research.

\section{References}

1 Anderson SA, Menis M, O'Connell K, Burwen DR: Blood use by inpatient elderly population in the United States. Transfusion 2007;47:582-592.

2 Beguin C, Closon MC, Vandekerckhove P, Baele P: Concentration of transfusion resources on a few pathologies and a few patients: analysis of the comprehensive in-hospital patient database. Transfusion 2007; 47:217-227.

3 Gombotz H, Rehak PH, Shander A, Hofmann A: Blood use in elective surgery: the Austrian benchmark study. Transfusion 2007;47:1468-1480.

${ }_{4}$ Seifried E, Klüter H, Weidmann C, Staudenmaier T, Schrezenmeier H, Henschler R, Greinacher A, Müller MM: How much blood is needed? Vox Sang 2011;100: $10-21$.

5 Brokent-Raven BA, Janssen MP, van der Poel CL, Schaasberg WP, Bonsel GJ, van Hout BA: The PRO TON study: profiles of blood product transfusion recipients in the Netherlands. Vox Sang 2010;99:54-64.

6 Geissler RG, Franz D, Buddendick H, Krakowitzky P, Bunzemeier H, Roeder N, Van Aken H, Kessler T, Berdel W, Sibrowski W, Schlenke P: Retrospective analysis oh the blood component utilization in a university hospital of maximum medical care. Transfus Med Hemother 2012;39:29-138.

7 Shahian DM, Edwards FH, Ferraris VA, Haan CK, Rich JB, Normand SLT, DeLong ER, O’Brien SM, Shewan CM, Dokholyan RS, Peterson ED: quality measurement in adult cardiac surgery: part 1 - conceptual framework and measure selection. Ann Thorac Surg 2007;83(4 suppl):S3-12.

8 O'Brien SM, Shahian DM, DeLong ER, Normand SLT, Edwards FH, Ferraris VA, Haan KC, Rich JB, Shewan CM, Dokholyan RS, Anderson RP, Peterson ED: Quality measurement in adult cardiac surgery: part 2 - statistical considerations in composite measure scoring and provider rating. Ann Thorac Surg 2007;83(4 suppl): S13-26.

9 Shander A: Blood transfusion as a quality indicator in cardiac surgery. JAMA 2010;304:1610-1611.
10 Funkat AK, Beckmann A, Lewandowski J, Frie M, Schiller W, Ernst M, Hekmat K: Cardiac surgery in Germany during 2011: a report on behalf of the German Society for Thoracic and Cardiovascular Surgery. Thorac Cardiovasc Surg 2012;60:371-382.

11 Wilson CT, Fisher ES, Welch HG, Siewers AE, Lucas FL: U.S. trends in CABG hospital volume: the effect of adding cardiac surgery programs. Health Aff 2007;26: 162-168.

12 Ali A, Auvinen MK, Rautonen J: The aging population poses a global challenge for blood services. Transfusion 2010;50:584-588.

13 Barr PJ, Donnelly M, Morris K, Parker M, Cardwell C, Baillie KEM: The epidemiology of red cell transfusion. Vox Sang 2010;99:239-250.

14 Greinacher A, Fendrich K, Hoffmann W: Demographic changes: the impact for safe blood supply. Transfus Med Hemother 2010;37:141-148.

15 Henseler O, Heiden M, Haschberger B, Hesse J, Seitz R: Report on notifications pursuant to $\$ 21$ German Transfusion Act for 2007. Transfus Med Hemother 2010;37: 29-47.

16 Wells AW, Mounter PJ, Chapman CE, Stainsby D, Wallis JP: Where dos blood go? Prospective, observational study of red cell transfusion in north England. BMJ 2002;325:803-806.

17 Weiser TG, Regenbogen SE, Thompson KD, Haynes AB, Lipsitz SR, Berry WR, Gawande AA: An estimation of the global volume of surgery: a modelling strategy based on available data. Lancet 2008;372:139-144.

18 Vamvakas EC, Taswell HF: Epidemiology of blood transfusion. Transfusion 1994;34:464-470.

19 Wallis JP, Wells AW, Matthews JN, Chapman CE: Long-term survival after blood transfusion: a population based study in the North of England. Transfusion 2004;44:1025-1032.

20 Ritter S, Willand L, Reinhard B, Offergeld R, Hamouda O: Demography and donation frequencies of blood and plasma donor populations in Germany. Bundesgesundheitsbl Gesundheitsforsch Gesundheitsschutz 2008;51: 915-925.
21 Ehling M, Pötzsch O: Demographic changes in Germany up to 2060 - consequences for blood donation. Transfus Med Hemother 2010;37:131-139.

22 Shander A, Van Aken H, Colomina MJ, Gombotz H, Hofmann A, Krauspe R, Lasocki S, Richards T, Slappendel R, Spahn DR: Patient blood management in Europe. Br J Anaesth 2012;109:55-68.

23 Yazer MH, Waters JH: How do I implement a hospitalbased blood management program? Transfusion 2012; 52:1640-1645.

24 Spahn DR, Moch H, Hofmann A, Isbister JP: Patient blood management: the pragmatic solution for the problems with blood transfusions. Anesthesiology 2008;109:951-953.

25 Spahn A: Anemia and patient blood management in hip and knee surgery. Anesthesiology 2010;113:482-495.

26 Goodnough LT, Maniatis A, Earnshaw P, Benoni G, Beris P, Bisbe E, Fergusson DA, Gombotz H, Habler O, Monk TG, Ozier Y, Slappendel R, Szpalski M: Detection, evaluation, and management of preoperative anemia in the elective orthopedic surgical patient: NATA guidelines. Br J Anaesth 2011;106:13-22.

27 Anker SD, Colet JC, Filippatos G, Willenheimer R, Dickstein K, Drexler H, Lüscher TF, Bart B, Banasiak W, Niegowska J, Kirwan BA, Mori C, von Eisenhart Rothe B, Pocock SJ, Poole-Wilson PA, Ponikowski P, for the FAIR-HF Trial Investigators: Ferric carboxymaltose in patients with heart failure and iron deficiency. N Engl J Med 2009;361:2436-2448.

28 Owings DV, Kruskall MS, Thurer RL, Donovan LM: Autologous blood donations prior to elective cardiac surgery. JAMA 1989;262:1963-1968.

29 Lewis CE, Hiratzka LF, Woods SE, Hendy MP, Engel AM: Autologous Blood transfusions in elective cardiac valve operations. J Card Surg 2005;20:513-518.

30 Hébert PC, Wells G, Blajchman MA, Marshall J, Martin C, Pagliarello G, Tweeddale M, Schweitzer I, Yetisir E, the Transfusion Requirements in Critical Care Investigators for the Canadian Critical Care Trials Group: A multicenter, randomized, controlled clinical trial of transfusion requirements in critical care. N Engl J Med 1999;340:409-417. 
-31 Carson Jl, Terrin ML, Noveck H, Sanders DW, Chaitman BR, Rhoads GG, Nemo G, Dragert K, Beaupre L, Hildebrand K, Macaulay W, Lewis C, Cook DR, Dobbin G, Zakriya KJ, Apple FS, Horney RA, Magaziner J, for the FOCUS Investigators: Liberal and restrictive transfusion in high-risk patients after hip surgery. N Engl J Med 2011;365:2453-2462.

-32 Spiess BD, Gillies BS, Chandler W, Verrier E: Changes in transfusion therapy and reexploration rate after institution of a blood management program in cardiac surgical patients. J Cardiothorac Vasc Anesth 1995;9:168-173.

33 Society of Thoracic Surgeons Blood Conservation Guideline Task Force, Ferraris VA, Ferraris SP, Saha SP, Hessel EA 2nd, Haan CK, Royston BD, Bridges CR, Higgins RS, Despotis G, Brown JR; Society of Cardiovascular Anesthesiologists Special Task Force on Blood Transfusion, Spiess BD, Shore-Lesserson L, Stafford-Smith M, Mazer CD, Bennett-Guerrero E, Hill SE, Body S: Perioperative blood transfusion and blood conservation in cardiac surgery: the Society of Thoracic Surgeons and the Society of Cardiovascular Anesthesiologists Clinical Practice Guideline. Ann Thorac Surg 2007;83(5 suppl):S27-86.

34 Society of Thoracic Surgeons Blood Conservation Guideline Task Force, Ferraris VA, Brown JR, Despotis GJ, Hammon JW, Reece TB, Saha SP, Song HK, Clough ER; Society of Cardiovascular Anesthesiologists Special Task Force on Blood Transfusion, Shore-Lesserson LJ, Goodnough LT, Mazer CD, Shander A, Stafford-Smith $\mathrm{M}$, Waters J; International Consortium for Evidence Based Perfusion, Baker RA, Dickinson TA, FitzGerald DJ, Likosky DS, Shann KG: 2011 Update to the Society of Thoracic Surgeons and the Society of Cardiovascular Anesthesiologists blood conservation clinical practice guidelines. Ann Thorac Surg 2011;91:944-982.
35 Hessel EA 2nd, Levy JH: Guidelines for perioperative blood transfusion and conservation in cardiac surgery: lessons and challenges. Anesth Analg 2010;111:15551559.

36 Hajjar LA, Vincent JL, Galas FR, Nakamura RE, Silva CM, Santos MH, Fukushima J, Kalil Filho R, Sierra DB, Lopes NH, Mauad T, Roquim AC, Sundin MR, Leão WC, Almeida JP, Pomerantzeff PM, Dallan LO, Jatene FB, Stolf NA, Auler JO Jr: Transfusion requirements after cardiac surgery: the TRACS randomized controlled trial. JAMA 2010;304:1559-1567.

37 Bennett-Guerrero E, Zhao Y, O’Brien SM, Ferguson TB Jr, Peterson ED, Gammie JS, Song HK: Variation in use of blood transfusion in coronary artery bypass graft surgery. JAMA 2010;304:1568-1575.

38 Roeder N, Siebers L, Frie M, Bunzemeier H: DRG-Akzeptanz verbessern - Kliniker erreichen mit klinischen Leistungsgruppen. Das Krankenhaus 2006;5:390-401.

39 Helling J, Bunzemeier H, Fiori W, Siebers L, Brüning K, Gaber A, Frie M, Babapirali J, Roeder N: Klinische Leistungsgruppen - Update und Ausblick. Das Krankenhaus 2009;9,857-862.

40 Murphy GJ, Reeves BC, Rogers CA, Rizvi SI, Culliford L, Angelini GD: Increased mortality, postoperative morbidity, and cost after red blood cell transfusion in patients having cardiac surgery. Circulation 2007;116:2544-2552.

41 Avidan MS, Alcock EL, Da Fonseca J, Ponte J, Desai JB, Despotis GJ, Hunt BJ: Comparison of structured use of routine laboratory tests or near-patient assessment with clinical judgement in the management of bleeding after cardiac surgery. Br J Anaesth 2004;92:178-186.
42 Engoren MC, Habib RH, Zacharias A, Schwann TA Riordan CJ, Durham SJ: Effect of blood transfusion on long-term survival after cardiac operation. Ann Thorac Surg 2002;74:1180-1186.

3 Murphy GJ, Angelini GD: Indications for blood transfusion in cardiac surgery. Ann Thorac Surg 2006;82 2323-2334.

44 Koch CG, Li L, Duncan AI, Mihaljevic T, Cosgrove DM, Loop FD, Starr NJ, Blackstone EH: Morbidity and mortality risk associated with red blood cell and bloodcomponent transfusion in isolated coronary artery bypass grafting. Crit Care Med 2006;34:1608-1616.

45 Koch CG, Li L, Van Wagoner DR, Duncan AI, Gillinov $\mathrm{AM}$, Blackstone EH: Red cell transfusion is associated with an increased risk for postoperative atrial fibrillation. Ann Thorac Surg 2006;82:1747-1756.

46 Rawn JD: Blood transfusion in cardiac surgery. A silent epidemic revisited. Circulation 2007;116:2523-2524.

47 Galas FRBG, Almeida JP, Fukushima JT, Osawa EA Nakamura RE, Silva CMPDC, Pinto Marinho de Almeida P, Auler JOC, Vincent JL, Hajjar LA: Blood transfusion in cardiac surgery is a risk factor for increased hospital length of stay in adult patients. J Cardiothorac Surg 2013;8:54-60.

48 Leal-Noval SR, Rincón-Ferrari MD, García-Curiel A, Herruzo-Avilés A, Camacho-Laraña P, GarnachoMontero J, Amaya-Villar R: Transfusion of blood components and postoperative infection in patients undergoing cardiac surgery. Chest 2001;119:1461-1468. 